\title{
Erratum
}

\section{Pathogenesis of lupus dermatoses in autoimmune mice} VI. Correlation between positivity of lupus band test and lupus nephritis

\author{
F. Furukawa, G. Ohshio, H. Tanaka, T. Nakamura, S. Ikehara, S. Imamura, and T. Hamashima
}

Departments of ${ }^{1}$ Dermatology and ${ }^{2}$ Pathology, Faculty of Medicine, Kyoto University, Sakyo, Kyoto 606, Japan

Arch Dermatol Res (1986) 278:343-346

An unfortunate error occurred in this article. The sentence reading the "MRL mice used in this experiment were male and BXSB mice were female" should have been "MRL mice used in this experiment were female and BXSB mice were male". 